\title{
Book Review: Understanding Human Anatomy and Pathology
}

\author{
Anne M. Burrows * \\ Physical Therapy, Duquesne University, Pittsburgh, PA, USA
}

Keywords: anatomy, pathology, evolution, textbooks as topic, development

\section{A Book Review on \\ Understanding Human Anatomy and Pathology: An Evolutionary and Developmental Guide} for Medical Students

Rui Diogo, Drew M. Noden, Christopher M. Smith, Julia Molnar, Julia C. Boughner, Claudia Alexandra Amorim Barrocas, Joana Araujo Bruno, (Boca Raton, FL: CRC Press), 2016, 330 pages, ISBN: 9781498753845.

This book is a welcome addition to the literature on human gross anatomy aimed at medical students. It's a combined text and atlas focused mainly on the head, neck, and limbs. This unique work pulls together our understanding on gross anatomy of these areas, evo-devo correlates, the evolutionary basis of some common pathologies, and informs the medical student (I would argue for dental students as well) of how some of these pathologies develop in an evolutionary light. The authors are highly qualified to put together this work. This sort of book will be useful for the medical and dental students who wish to be able to talk to their patients about pathologies, to be able to understand the appearance of various pathologies of the head/neck and limbs, and to gain a deeper understanding of human anatomy.

The organization of this book is clear and logical. Chapter 1 talks a bit about the impetus for

OPEN ACCESS

Edited by:

Rui Diogo,

Howard University, USA

Reviewed by: Kate Mary Trinajstic

Curtin University, Australia

${ }^{*}$ Correspondence: Anne M. Burrows burrows@duq.edu

Specialty section:

This article was submitted to Evolutionary Developmental Biology, a section of the journal

Frontiers in Ecology and Evolution

Received: 07 September 2016 Accepted: 27 September 2016 Published: 13 October 2016

Citation:

Burrows AM (2016) Book Review: Understanding Human Anatomy and Pathology. Front. Ecol. Evol. 4:120 doi: 10.3389/fevo.2016.00120 writing this book and Chapter 2 gives a succinct yet informative background on how human anatomy and its associated terminology developed out of terminology used for quadrupedal animals. Terminology associated with human anatomy can be confusing for a variety of students, words such as "dorsal," "ventral," and the terms "extension" and "flexion" for various parts of lower limb joints. Diogo and co-authors do a good job of explaining lower limb joint movements by appreciating the evolutionary and developmental aspects of human development plus the inclusion of comparative anatomy. This chapter sets up the framework for the rest of the book. In my experience, medical and dental students who have a grasp on evolutionary and comparative anatomy do well in clinical rotations as well as research rotations and the material in this chapter would help them tremendously in setting up their understanding. The embryology plates accompanying this section are well done and informative.

Chapter 3 focuses on the Head and Neck, possibly the two the most daunting anatomical regions for students. The first section of this chapter does a good job breaking down the evolutionary importance of neural crest cells, what they do, and relatively new work that demonstrates developmental connections between the heart and musculature of the head and neck. Box 3.2 and Figure 3.1 are outstanding summaries of these connections. This chapter includes an exhaustive collection of osteological landmarks of the cranium, foramina and their contents, and a good but succinct review of the branchial arches and their derivatives. The plate showing branchial arch fates is well done and includes information on how Hox genes fit into the picture of head/neck development.

Cranial nerves cause most anatomy students to cringe. The sections in Chapter 3 dealing with cranial nerves is a detailed but meaningful summary of the nerves, their pathways through pertinent foramina, and their target structures. The plates accompanying this section are well drawn, easy to 
see, but for my taste the writing is a bit small. Given the compact, portable nature of this book, there's not much the authors could do about that. The authors also devote space in this chapter to the muscles derived from each branchial arch and their cranial nerve innervation. The rich tables in this chapter are helpful for organizing information. Similarly, the sections detailing vasculature of the head and neck are well organized, richly illustrated, and easy to understand.

Chapters 4, 5 deal with the upper limb and lower limb, respectively. These anatomical regions may not terrorize students as intensely as the head and neck, but the limbs have their challenges in any gross anatomy course. As in previous chapters, the section in Chapter 4 dealing with embryology of the upper limb (Box 4.2) goes a long way to explaining the functional anatomy of the limb. Most anatomy students are flabbergasted by the brachial plexus, at least for a little while. The authors do a good presentation of the brachial plexus in this chapter, giving "tricks" to remember origin, pathway, and targets of many of the terminal branches. Similar methodologies are used for describing the vasculature of the upper limb. The black and white figures in Chapter 4 are clear, concise, and well-labeled. The tables organizing upper limb musculature in evo-devo groupings may be especially helpful for students trying to figure out how to organize the information for studying purposes. My only complaint on Chapter 4 is that I wish the authors would have spent more time calling out the evolutionary anatomy of the carpal tunnel and how it relates to carpal tunnel syndrome.

The lower limb is presented in Chapter 5 and the authors similarly tightly organize musculature in tables. I would like to have seen a section in Chapter 5 devoted to the functional anatomy of the human gait cycle but that's a minor note in an otherwise tightly organized and informative chapter.
The final chapter in the book, Chapter 6, is devoted to the trunk. Muscles of the deep back are almost always a nightmare for anatomy students, due in part to their attachments to one another. The authors have succinctly described the deep back muscles with their functions but I would have liked to see some tie-in with evolutionary anatomy and how these muscles function in quadrupeds vs. us bipeds. There are great sections in this chapter on the evolution of Hox genes, their role in setting up the axial skeleton, and their part in development of various childhood cancers.

One problem in this book is the absence of information on the lungs as well as structures of the abdominal and pelvic cavities. What is present in the book is well done, valuable to any medical or dental student, and goes a long way toward helping student organize information related to the head/neck, limbs, and trunk. Given the compact size of the book, it would be a wise investment for students in gross anatomy.

\section{AUTHOR CONTRIBUTIONS}

The author confirms being the sole contributor of this work and approved it for publication.

Conflict of Interest Statement: The author declares that the research was conducted in the absence of any commercial or financial relationships that could be construed as a potential conflict of interest.

Copyright $(2) 2016$ Burrows. This is an open-access article distributed under the terms of the Creative Commons Attribution License (CC BY). The use, distribution or reproduction in other forums is permitted, provided the original author(s) or licensor are credited and that the original publication in this journal is cited, in accordance with accepted academic practice. No use, distribution or reproduction is permitted which does not comply with these terms. 